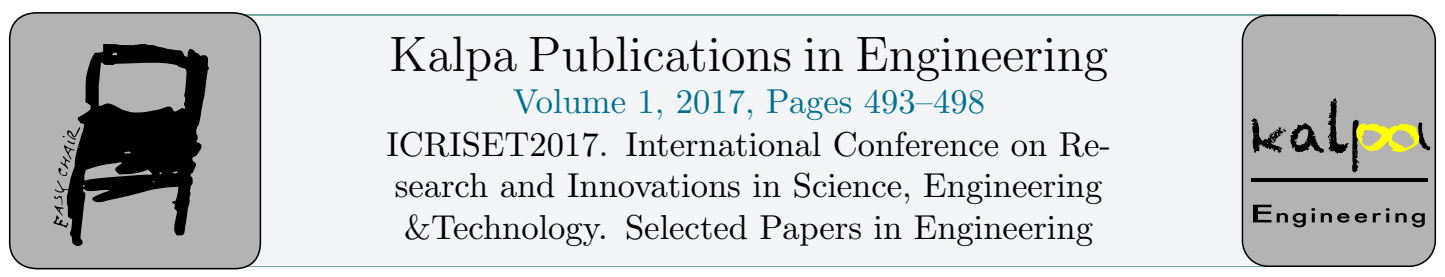

\title{
Automated Spur Gear Designing Using MATLAB
}

\author{
Shashvat Mehta ${ }^{1}$ and Mitesh Panchal ${ }^{2}$ \\ ${ }^{1}$ Student, ${ }^{2}$ Assistant Professor, Department of Mechanical Engineering \\ Institute of Technology, Nirma University, Ahmedabad, Gujarat, India \\ Shashvat153egmail.com, mitesh.panchalenirmauni.ac.in
}

\begin{abstract}
This paper describes the design procedure of a spur gear and the selection of appropriate module of a spur gear according to the requirements using Matlab. Along with the module, the other gear and gear teeth parameters are also found and pertaining to these results, simulation and analysis is carried out to ensure the efficient working of the designed gear in the field.
\end{abstract}

\section{Introduction}

Gear design is a process in which depending on the requirements, appropriate gear parameters are calculated. The requirements of gear vary, and due to this the gear design changes. The matlab code written here uses the design requirements, and performs the calculations to arrive at the module of the gear. This module found is used to calculate other parameters of the gear such as addendum, dedundum, clearance, working depth, whole depth, clearance, outer diameter, and the factor of safety.

These obtained results are used to create a solid model of the spur gear in solid modeling software. Subsequently, simulation and analysis is carried out to find the stresses generated and to ensure that it is within the constraints defined by the factor of safety. In this code, we prefer involute profile to cycloid profile as in accordance with reality

\section{Gear design based on Beam strength}

For a gear tooth, two profiles are widely accepted. Cycloidal profile and Involute profile. Both have their own pros and cons. Cycloidal tooth do not have the problem of interference and their working is smooth and efficient. However, their manufacturing is difficult. Involute tooth have the problem of interference and their operation is noisy, but their manufacturing is easy and a slight change in the center distance is tolerable. 
There are three standard involute gear tooth systems depending on the pressure angle. They are $14.5^{\circ}$ full depth system, $20^{\circ}$ full depth system and $20^{\circ}$ stub system. With each tooth system, standard involute teeth proportions have been defined in table 1, where $m$ stands for module. These standard proportions are followed in the matlab code. The solution for the problem considered assumes a $20^{\circ}$ full depth system.

\begin{tabular}{|c|c|c|c|}
\hline \multicolumn{4}{|c|}{ Gear tooth parameters as multiples of module } \\
\hline & $\begin{array}{c}14.5^{\circ} \text { full } \\
\text { depth. }\end{array}$ & $\begin{array}{c}20^{\circ} \text { full } \\
\text { depth }\end{array}$ & $20^{\circ}$ stub \\
\hline Pressure Angle & 14.5 & 20 & 20 \\
\hline Addendum & $\mathrm{m}$ & $\mathrm{m}$ & $0.8 \mathrm{~m}$ \\
\hline Dedundum & $1.157 \mathrm{~m}$ & $1.25 \mathrm{~m}$ & $\mathrm{~m}$ \\
\hline Clearance & $0.157 \mathrm{~m}$ & $0.25 \mathrm{~m}$ & $0.2 \mathrm{~m}$ \\
\hline Working depth & $2 \mathrm{~m}$ & $2 \mathrm{~m}$ & $1.6 \mathrm{~m}$ \\
\hline Whole depth & $2.157 \mathrm{~m}$ & $2.25 \mathrm{~m}$ & $1.8 \mathrm{~m}$ \\
\hline Tooth thickness & $1.52708 \mathrm{~m}$ & $1.5270 \mathrm{~m}$ & $1.5270 \mathrm{~m}$ \\
\hline
\end{tabular}

Table 1: Standard Tooth systems

In gear systems, the force is transmitted from the tooth of driving gear to the tooth on driven gear by meshing. This force always acts along the pressure line. This force can be split into two components, a tangential and a radial component. The tangential component is our focus as it determines the torque and subsequently the power being transmitted. The radial component is a separating force and is directed towards the centre of the gears. The torque being transmitted for a given power and speed of transmission and the forces acting are as follows

$$
\begin{gathered}
M_{t}=\frac{60 * 10^{6} * \text { power }(\mathrm{kW})}{2 * \pi * \text { speed of rotation }(\mathrm{rps})} \\
P_{t}=\frac{2 * M_{t}}{d^{\prime}} \\
P_{r}=P_{t} * \tan \alpha \\
P_{N}=\frac{P_{t}}{\cos \alpha}
\end{gathered}
$$

These values are used to calculate the module of the gear. These formulas are based on the assumptions that the force $\mathrm{P}_{\mathrm{N}}$ is static, and only one set of teeth transmits complete load and the load is static throughout. As represented in the figure, the force $P_{N}$ is divided into two components $P_{t}$ and $P_{r}$ and the angle $\alpha$ being the pressure angle of the meshing gears. The tangential force on the driven gear is along the direction of motion and the corresponding equal tangential force on the driving gear is opposite to the direction of the motion. The radial force on both the gears is compressive towards their respective centers.

The tangential force acting on the gear tooth causes the bending of the gear tooth about the base of the tooth. This criterion is used for deciding the appropriate parameters of the tooth. This theory was 
formulated assuming the effect of the radial forces to be negligible, the effect of stress concentration is neglected and only one pair of meshing gear teeth is in contact at any given time.

The cross-section area of the gear tooth varies from the base to the top land of the tooth. To balance the results, a parabola is assumed within the profile. The parabola beam has uniform stress distribution at any cross-section. Defining $\sigma_{\mathrm{b}}$ as the bending stress, $b$ as the face width, $m$ as the module, $t$ as the thickness of the base, and $h$ as the height of the parabola we have

$$
\begin{gathered}
P_{t}=m * b * \sigma_{\mathrm{b}} *\left(\frac{t^{2}}{6 * h * m}\right) \\
Y=\left(\frac{t^{2}}{6 * h * m}\right) \\
P_{t}=m * b * \sigma_{\mathrm{b}} * Y
\end{gathered}
$$

The above equations give the relationship between the stress value $\sigma_{b}$ and the tangential force $P_{t}$. The constant $Y$ is known as the Lewis form factor. The tangential force for which the stress value equals the permissible bending stress is known as the beam strength, denoted by $S_{b}$.

$$
S_{b}=m * b * \sigma_{\mathrm{b}} * Y
$$

The above equation is known as the Lewis equation (1). The gear tooth must not fail under bending and so the beam strength must be greater than the tangential force acting on the gear tooth. The quantities module $m$ and the face width $b$ remain the same for both the gears. The product $\left(\sigma_{\mathrm{b}} *\right.$ $Y$ ) decides the weaker between the two gears. The Lewis factor for corresponding number of teeth is as follows

\begin{tabular}{|l|l|l|l|l|l|}
\hline $\mathbf{z}$ & $\mathbf{Y}$ & $\mathbf{z}$ & $\mathbf{Y}$ & $\mathbf{z}$ & $\mathbf{Y}$ \\
\hline 15 & 0.289 & 27 & 0.348 & 55 & 0.415 \\
\hline 16 & 0.295 & 28 & 0.352 & 60 & 0.421 \\
\hline 17 & 0.302 & 29 & 0.355 & 65 & 0.425 \\
\hline 18 & 0.308 & 30 & 0.358 & 70 & 0.429 \\
\hline 19 & 0.314 & 32 & 0.364 & 75 & 0.433 \\
\hline 20 & 0.320 & 33 & 0.367 & 80 & 0.436 \\
\hline 21 & 0.326 & 35 & 0.373 & 90 & 0.442 \\
\hline 22 & 0.330 & 37 & 0.380 & 100 & 0.446 \\
\hline 23 & 0.333 & 39 & 0.386 & 150 & 0.458 \\
\hline 24 & 0.337 & 40 & 0.389 & 200 & 0.463 \\
\hline 25 & 0.340 & 45 & 0.399 & 300 & 0.471 \\
\hline 26 & 0.344 & 50 & 0.408 & Rack & 0.484 \\
\hline
\end{tabular}

Table 2: Lewis factor for corresponding number of teeth

The tooth of a gear comes under periodic bending stresses while transmitting the power. The driving gear teeth and driven gear teeth have induced stresses in one direction only. As the induced stresses are fluctuating, the design criterion for the material will be the endurance limit $S_{e}$. The maximum bending stress which can be sustained is equal to the endurance limit. Earle Buckingham [2] has simplified this concept that the endurance limit of a gear tooth can be taken to be equal to onethird of the ultimate tensile strength of the material, $S_{u t} \sigma_{b}=S_{e}=\left(\frac{1}{3}\right) * S_{u t}$

In reality, the torque produced by the source varies, and the torque delivered varies. This is taken care by a flywheel. While designing a gear, we selected the maximum force as the criterion. This change is accounted by a service factor, $C_{s}$. During low speeds, the transmitted load can be accounted to be the actual load in between the two meshing teeth. 


$$
C_{s}=\frac{\text { Maximum torque }}{\text { Rated torque }}
$$

However, at high speeds, the impact between two gear teeth gives rise to a dynamic force and this need to be considered for the design process. This dynamic force arises due to misalignment, inertia, inaccuracy, manufacturing error, etc. For the approximate estimation of this force, Velocity factor $C_{v}$ has been developed by Barth and is shown in table 3 .

\begin{tabular}{|c|c|}
\hline Ordinary gears with $\mathrm{v}<10 \mathrm{~m} / \mathrm{s}$ & $C_{v}=\frac{3}{3+v}$ \\
\hline $\begin{array}{c}\text { Accurately generated gears with } \mathrm{v}<20 \\
\mathrm{~m} / \mathrm{s}\end{array}$ & $C_{v}=\frac{6}{6+v}$ \\
\hline $\begin{array}{c}\text { Precision gears generated with grinding, } \\
\text { lapping operations with } \mathrm{v}>20 \mathrm{~m} / \mathrm{s}\end{array}$ & $C_{v}=\frac{5.6}{5.6+\sqrt[2]{v}}$ \\
\hline
\end{tabular}

Table 3: Velocity factor

\section{Gear design based on Wear strength}

If the contact stresses at the mating teeth exceed the surface endurance strength of the material,, pitting occurs. Pitting is a fatigue failure and forms small pits on the tooth surface. Earle Buckingham (2) carried out this analysis and formulated an equation to find the wear strength of the gear tooth. If the contact stresses exceed the surface endurance strength, pitting occurs. The maximum load the gear tooth is able to transmit without pitting failure is known as the wear strength of the gear tooth. The load stress factor $K$ defined in this theory is as follows,

$$
K=\frac{\sigma_{c}{ }^{2} * \sin \alpha * \cos \alpha *\left(\frac{1}{E_{1}}+\frac{1}{E_{2}}\right)}{1.4}
$$

Here, $\sigma_{c}$ is the maximum compressive stress, $\alpha$ is the pressure angle, $E_{1}$ and $E_{2}$ are the modulus of elasticity of the materials of the two mating gears. For gears made of steel and with pressure angle of $20^{\circ}$, this equation reduces to

$$
K=0.156\left(\frac{B H N}{100}\right)^{2}
$$

BHN is the Brinell hardness number of steel. For an efficient design, the wear strength must be greater than the force between two mating teeth. Ratio factor $Q$ is defined in this theory as, where $p$ subscript is for driving gear and $g$ subscript is for driven gear.

$$
Q=\frac{2 * z_{p}}{z_{g}+z_{p}}
$$

The module by wear strength is calculated as follows,

$$
m=\left(\frac{\left(60 * 10^{6}\right) * \operatorname{Power}(k W) * C_{s} * F O S}{\pi * z^{2} * n * C_{v} * \frac{b}{m} * Q * K}\right)^{\frac{1}{3}}
$$


Wear strength checks the gear tooth under wear condition i.e. pitting. Pitting due to interference also occurs in involute profile teeth, which is not due to overloading but due to the design. This can be eliminated by undercutting the tooth profile.

\section{The working of the matlab code}

The matlab code written takes the input of power transmission required, the required factor safety and the speed of the driving gear. Necessary material characteristics for both the materials need to be provided, the service factor for the source of driving gear, width-to-module ratio, and the pressure angle preferred.

Based on the above inputs, the matlab code will select the appropriate number of teeth on the gears for correct speed transmission. The list for the Lewis factor $Y$ for the respective number of teeth on a gear is included in the code. The Lewis factor $Y$ will automatically will be selected for both the gears. According to Earle Buckingham's theory (2), the permissible bending stress is calculated as one-thirds of the ultimate tensile strength of the material. Then the product of the permissible bending stress and the Lewis factor is carried out for both the gears. As discussed earlier, the lesser of these two values will be the critical value and the design procedure will be carried out for this gear. If our design will be as required for this gear, it will be safe for the other gear also.

These formulas are written in the code and the software uses those codes and provides us with the nearest module from the input list of the preferred modules, on the higher side so that the requirement of the factor of safety is satisfied. Based on this module, other parameters like addendum, dedundum, clearance, whole depth, working depth, and tooth thickness are calculated. Along with that, the pitch circle diameter of the gears, their respective face width and the factor of safety is also calculated.

According to wear formula, to resist the gear surface against pitting, the module and the load stress factor are related, and with the formula included in the code, the software also calculates the required ratio factor $Q$ and then using the input values and the above mentioned ratio factor and the calculated module, the required surface hardness in terms of BHN is calculated and displayed. In this way, all the parameters of the gears as well as the surface hardness are calculated.

Taking an example, there is a requirement to transmit $22.5 \mathrm{~kW}$ power with a factor of safety 1.5 . The driving gear is rotating at $1440 \mathrm{rpm}$ and the ultimate tensile strength of driving pinion and the driven gear to be $410 \mathrm{~N} / \mathrm{mm}^{2}$ and $200 \mathrm{~N} / \mathrm{mm}^{2}$ respectively. The number of teeth on the driving gear and the driven gear are selected as 20 and 50 respectively. The width-to-module ratio is taken as 10 . The service factor for the source is taken as 1.5.

The software gives the output for this data as the module of $8 \mathrm{~mm}$, addendum as $8 \mathrm{~mm}$, dedundum $10 \mathrm{~mm}$, clearance $2 \mathrm{~mm}$, working depth $16 \mathrm{~mm}$, whole depth $18 \mathrm{~mm}$, and the tooth thickness as $12.5664 \mathrm{~mm}$. The pitch circle diameter for the pinion is $160 \mathrm{~mm}$ and the pitch circle diameter for the gear is $400 \mathrm{~mm}$. These input values and the module calculated is again used to calculate the hardness, which comes out around to be $250 \mathrm{BHN}$. A gear hardened to this number will not fail under pitting or wear condition. The calculations can be carried out for all three-gear tooth systems.

\section{Confirming the results with a simulation software}

For the results obtained above, a solid model with the obtained dimensions is created in a 3D modeling software. Then, appropriate forces are applied to a gear tooth and the results produced are recorded. From these results, we come to know that the stress values are well below the maximum value and the factor of safety is higher than the required. 
The matlab code works successfully and gives us accurate results as proved by the simulation software.

\section{Conclusion}

The required factor of safety for the problem is 1.5 . The factor of safety for the calculated gear design comes out to be 1.56 . The effective load being transferred is $8402 \mathrm{~N}$ and the beam strength of the tooth is $13056 \mathrm{~N}$. The requirement is satisfied for the critically weaker gear and so the stronger gear will sustain it. Thus, we conclude that our matlab code gives accurate values of the gear parameters and maintains the required factor of safety.

The matlab code generates accurate results and it is proved by simulating a similar scenario in software and analyzing it. The spur gear design using matlab can further be extended to include helical gears, bevel gears as well as worm and worm wheels. Moreover, additional features such as undercutting, crowning, hunting, etc. can also be included in this matlab code so that all such parameters' dimensions can be calculated at once in a single run of the software.

\section{Acknowledgements}

Shashvat Mehta would like to thank Prof. Mitesh Panchal for his guidance and support during the preparation of this paper. He would also like to thank Institute of Technology, Nirma University for providing the resources to carry out this research work.

\section{References}

1. Investigation of the strength of gear teeth. Lewis, Willy. s.1. : Engineer's Club of Philadelphia, 1892.

2. Bhandari, V B. Design of Machine Elements. s.l. : McGraw Hill Education (India) Private Limited, 2014. 9780070681798.

3. Dynamic loads on gear tooth. Buckingham, Earle. New York: ASME Research publication, 1931.

4. Dudley, Darle W. and Radzevich, Stephen P. Handbook of practical gear design. s.l. : CRC Press, 1994. 